\title{
AUDIT SISTEM INFORMASI
}

SMK FARMASI CENDIKIA FARMA HUSADA

(DEVISI SARPRAS)

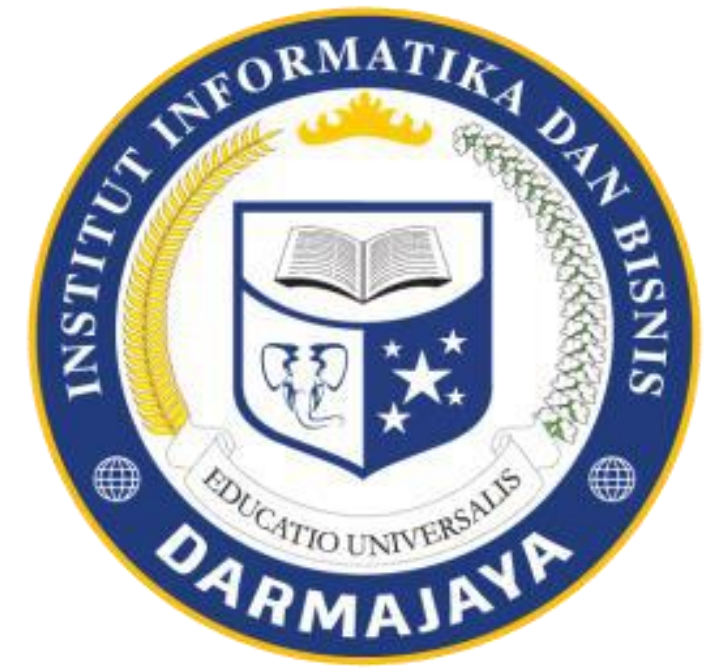

Yesi Herawati

1611050156

INSTITUT INFORMATIKA DAN BISNIS DARMAJAYA 2019 


\section{BAB I}

\section{SEJARAH SMK FARMASI CENDIKIA FARMA HUSADA}

Sekolah menengah kejuruan (SMK) farmasi cendikia farma husada dirintis sejak mei 2010 oleh praktisi apotikermuda yang berfossional dan kompeten dibidang kefarmasian yaitu Bpk.Hi ardyansyah khauripan, M,Si., Apt dibawah naungan yayasan cendikia farma husada.

SMK farmasi candika husada ini merupakan smk farmasi yang pertama berada diBandar Lampung yang kemuduan menjadi pelopor perkembangan smk farmasi diprovinsi Lampung. Sebagai sekolah farmasi plopor, SMK farmasi cendika terus melakukan pengebangan sistem kependiddikan farmasi sehinga tampil menjadi SMK farmasi favorit dan unggul.

Secara geografis gedung SMK farmasi cendikia farma husada terletak dilingkingan pemungkiman penduduk dikota Bandar Lampung tempatnya dijalan pulau enggano No.99, Kelurahan Sukabumi, Kecamatan Sukabumi, kota Bandar Lampung. Sekolah ini berdiri diatas tanah seluas $\pm 1.878 \mathrm{~m}^{2}$.

Secara topografi wilayah SMK farmasi cendikia farma husada merupakan daerah dataran yang subur dengan sumber air yang baik. Akses menuju sekolah dapat ditempuh dengan roda empat maupun roda dua.

Tata ruang gedung SMK farmasi candikia farma husada dibangun dengan konsep modren dan humanis sehingga interaksi guru dan siswa dalam proses pendidikan dapat terbangun dan terpelihara dengan baik. SMK farmasi candikia farma husada menyajikan fasilitas belajar yang nyaman dan memadai yaitu:

1. Gedung sekolah yang fresh dengan status milik sendiri (yayasan cendikia farma husada).

2. Laborarorium praktikum farmasetika yang lengkap dan ber-AC.

3. Ruang kelas multimedia (audio-visual/lcd proyektor) dan ber $-\mathrm{AC}$.

4. Wifi/host spot area.

5. Perpustakaan

6. Kantin yang bersih dan nyaman

7. Mushola

8. Ruang perawatan kesehatan

9. Ruang sekretariat bersama unit kegiatan siswa

10. Lapangan bulu tangkis dan sepak takraw

11. Area parkir dan taman

12. Apotek pendidikan

13. Kebun tanaman obat

14. Fasilitas sanitasi yang baik.

Letak sekolah yang tidak terlalu dekat dengan jalan raya menjadi nilai positif secara ekologis, sekolah tiadak bisik dan mengurangi kontaminasi dari polusi timbal yang berbahaya bagi pernafasan. Letak sekolah yang lebih tinggi dari jalan umum serta sistem irigasi yang lancar dan baik dapat menghindari sekolah dari banjir pada musim hujan. Tanaman dan sirkulasi 
udara yang ditata dengan baik sangat mendukung kenyamanan dalam proses belajar selama masa pendididkan serta dapat menjaga kesehatan dilingkingan sekolah.

\section{VISI DAN MISI SMK FARMASI CENDIKIA FARMA HUSADA}

* VISI

"mewujudkan sekolah yang unggul dalam mencetak asisten tenaga kefarmasian yang kompeten,disiplin,religius dan berdaya saing".

\section{MISI}

1. Membangkitan kekuatan moral dan kesadaran tentang keberadaan Allah SWT Yang Masha Esa dan sadar bahwa setiap kehidupan akan dipertanggung jawabkan .

2. Menyelenggarakan proses pendidikan yang professional dan berkualitas agar peserta didik menjadi asisten tenaga kefarmasian yang berkemampuan akademik dan berdaya asing.

3. Melakukan pendidikan dan pengembangan karakter peserta didik agar memiliki kecerdasan emosional dan spiritual yang baik dalam menerapkan ilmu kefarmasian dimasyarakat.

4. Menggunakan teknologi informasi dalam penyelenggaraan pendidikan serta mengupayakan kemampuan penggunananya kepada peserta didik untuk meningkatkan daya asing diera digital.

\section{FRESTASI SMK FARMASI CENDIKIA FARMA HUSADA}

1. Juara $1 \mathrm{lks}$ tingkat kota bandar lampung

2. Juara 1 olimpiade sains terapan (ost) bidang biologi se provinsi lampung

3. Juara 1 lomba kompetisi siswa (lks) se provinsi lampung

4. Smk faramasi cendikia farma husada mendapat penghargaan dari mentri pendididkan nasional RI sebagai sekolah berintegritas tinggi tahun 2015

\section{SMK FARMASI CENDIKIA FARMA HUSADA BERGERAK DIBIDANG}

"Yayasan Cendikia Farma Husada”

\section{DENAH LOKASI SMK FARMASI CENDIKIA FARMA HUSADA}

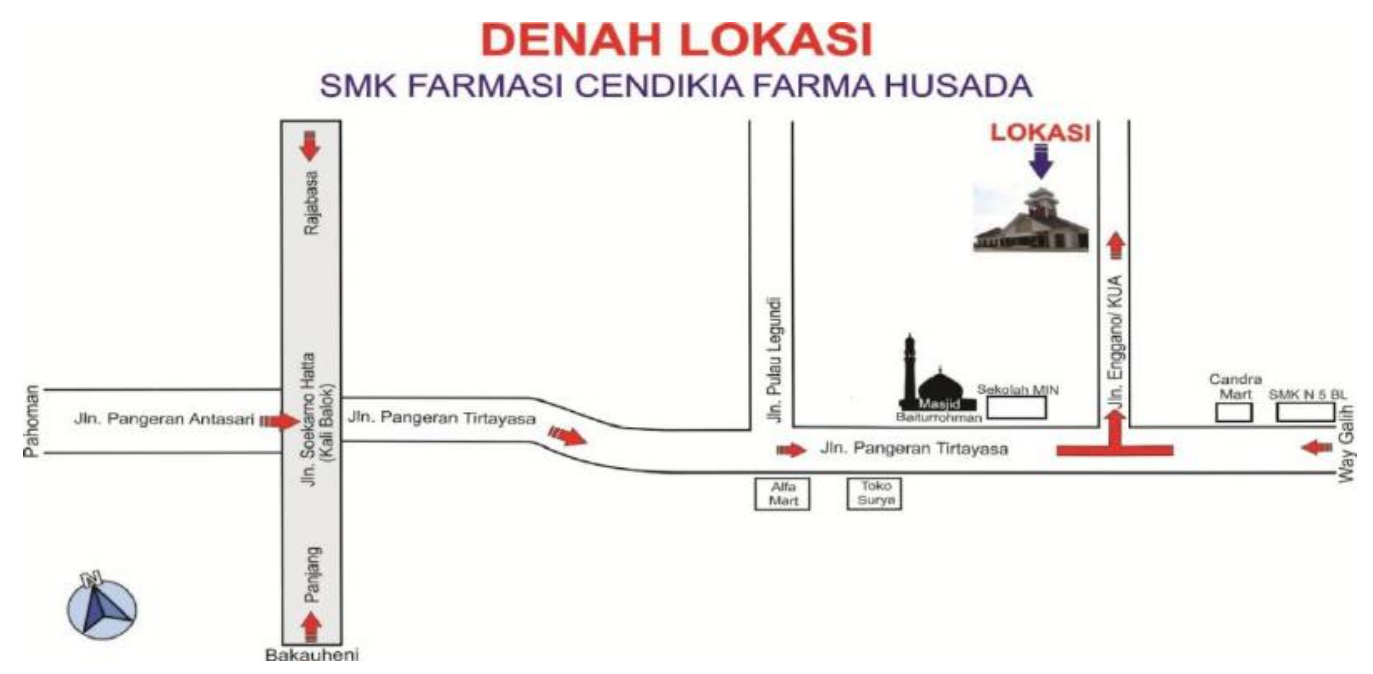




\section{BAB II}

\section{STRUKTUR SMK FARMASI CENDIKIA FARMA HUSADA}

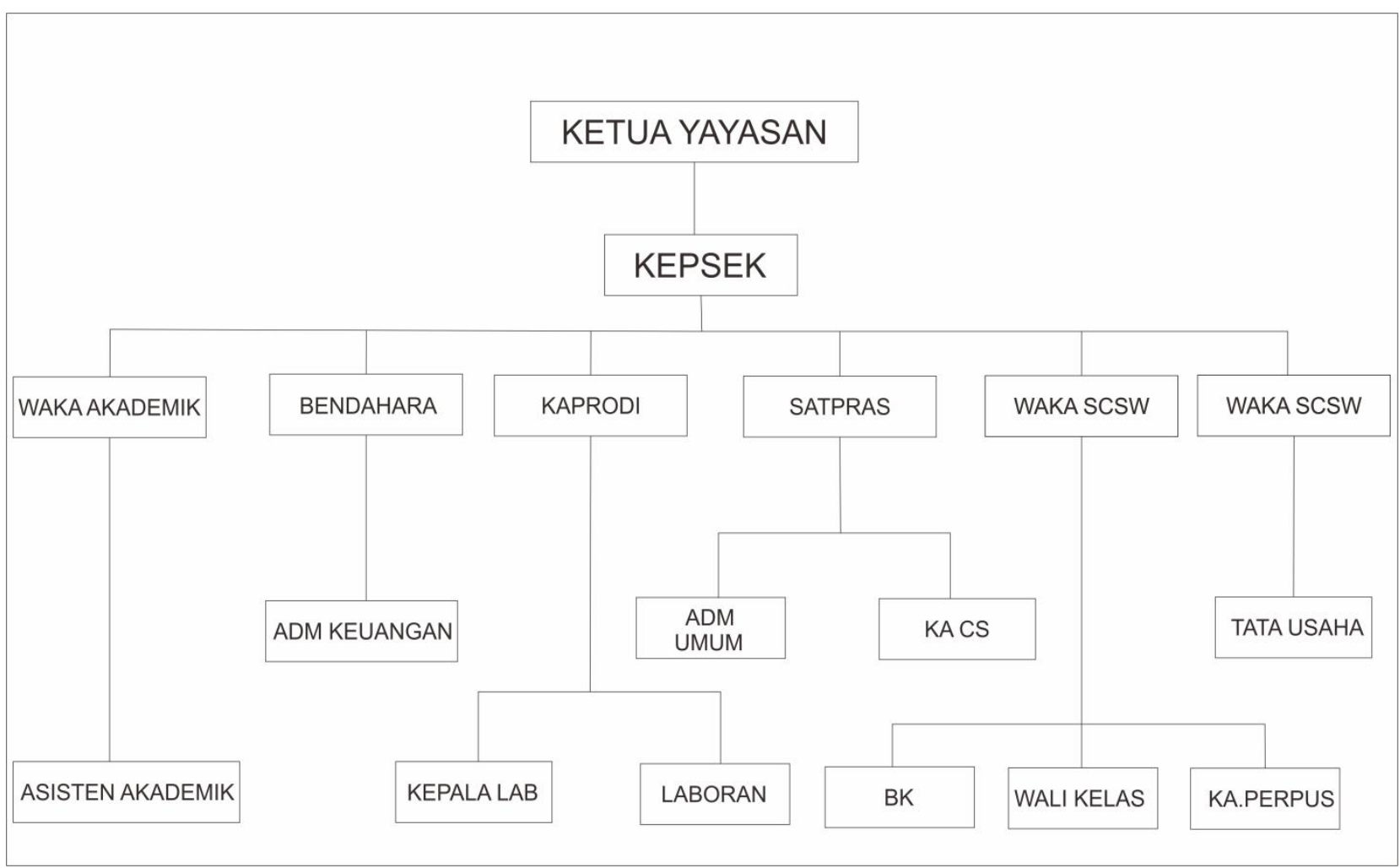

\section{STRUKTUR DIVISI SARPRAS}

STRUKTUR DIVISI SATPRAS

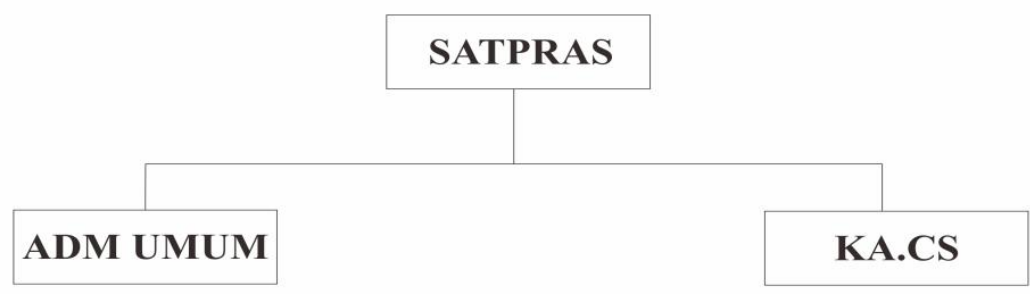




\section{BAB III}

Quisioner Manajement P0.4

\begin{tabular}{|c|c|c|c|c|c|c|c|c|c|c|c|}
\hline \multirow{2}{*}{ No. } & \multirow{2}{*}{ Persyaratan } & \multicolumn{5}{|c|}{ Performance } & \multicolumn{5}{|c|}{ Expectasi } \\
\hline & & SB & $\mathrm{B}$ & $\mathrm{C}$ & $\mathrm{TB}$ & STR & SB & $\mathrm{B}$ & $\mathrm{C}$ & $\mathrm{TB}$ & STR \\
\hline \multicolumn{12}{|c|}{ P04 Mendefinisikan Proses TI,Organisasi,Dan Hubungan TI } \\
\hline \multicolumn{12}{|c|}{ P04.1 Rangka Proses IT } \\
\hline 1. & $\begin{array}{l}\text { Apakah informasi dalam hal sarana } \\
\text { dan prasarana sudah } \\
\text { terkomputerisasi?. }\end{array}$ & & & & & & & & & & \\
\hline 2. & $\begin{array}{l}\text { Bagaimana pelaksanaan dan } \\
\text { penyusunan informasi dalam hal } \\
\text { sarana dan prasarana siswa. }\end{array}$ & & & & & & & & & & \\
\hline \multicolumn{12}{|c|}{ P04.2 Komite strategi IT } \\
\hline 1. & $\begin{array}{l}\text { bagaimana sekolah menyampaikan } \\
\text { sarana dan prasarana secara online } \\
\text { kepada siswa? }\end{array}$ & & & & & & & & & & \\
\hline 2. & $\begin{array}{l}\text { Apakah pengumuman pemberitahuan } \\
\text { sarana dan prasarana sudah secara } \\
\text { online melalui website sekolah? }\end{array}$ & & & & & & & & & & \\
\hline \multicolumn{12}{|c|}{ P04.3 Komite pengarah IT } \\
\hline 1. & $\begin{array}{l}\text { Apakah setiap tahun ajaran baru } \\
\text { sekolah mengumumkan tentang hal } \\
\text { sarana dan prasarana? }\end{array}$ & & & & & & & & & & \\
\hline 2. & $\begin{array}{l}\text { Bagaimana sekolah mengintruksikan } \\
\text { siswanya untuk menjaga sarana dan } \\
\text { prasarana yang ada disekolah maupun } \\
\text { kelas? }\end{array}$ & & & & & & & & & & \\
\hline \multicolumn{12}{|c|}{ P04.4 Penempatan Organisasi Pada Fungsi TI } \\
\hline 1. & $\begin{array}{l}\text { Apakah sarana dan prasarana sudah } \\
\text { sesuai dengan kebutuhan sekolah }\end{array}$ & & & & & & & & & & \\
\hline 2. & $\begin{array}{l}\text { bagaimana sekolah membuat agar } \\
\text { data sarana dan prasarana yang } \\
\text { dilakukan secara online atau manual } \\
\text { tersebut tidak terjadi kesalahan dalam } \\
\text { data sarana dan prasarana sekolah? }\end{array}$ & & & & & & & & & & \\
\hline \multicolumn{12}{|c|}{ P04.5 Struktur Organisasi IT } \\
\hline 1. & $\begin{array}{l}\text { Bagaimana struktur organisasi yang } \\
\text { berjalan dibagian sarana dan } \\
\text { prasarana }\end{array}$ & & & & & & & & & & \\
\hline 2. & $\begin{array}{l}\text { Apakah pada bagian sarana dan } \\
\text { prasarana terdapat wali kelas yang } \\
\text { bekerja sama untuk menjaga sarana } \\
\text { dan prasarana yang ada disetiap } \\
\text { kelas? }\end{array}$ & & & & & & & & & & \\
\hline
\end{tabular}




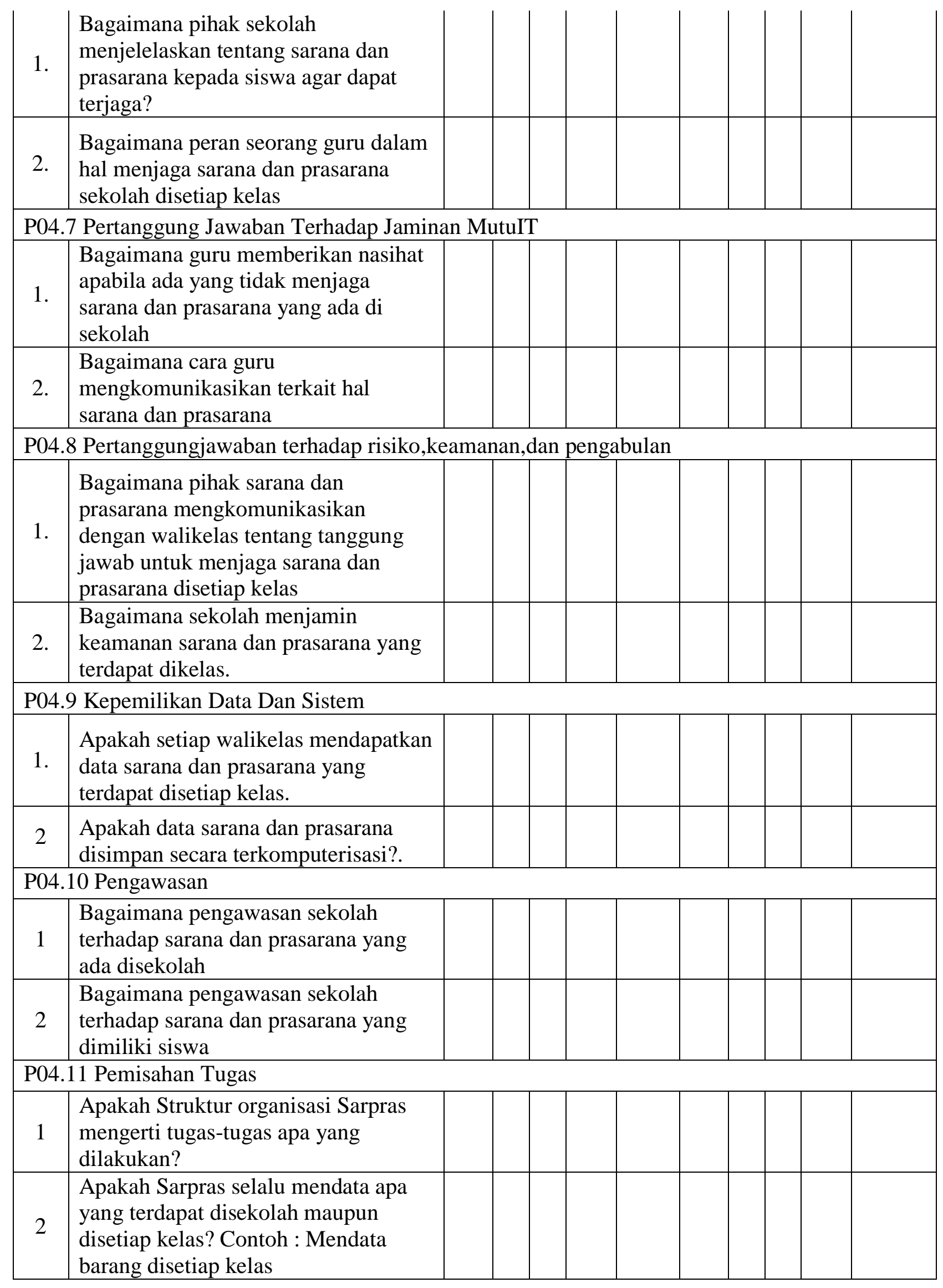


> Quisioner Manajement AI5

\begin{tabular}{|c|c|c|c|c|c|c|c|c|c|c|c|}
\hline \multirow{2}{*}{ No. } & \multirow{2}{*}{ Persyaratan } & \multicolumn{5}{|c|}{ Performance } & \multicolumn{5}{|c|}{ Expectasi } \\
\hline & & SB & $\mathrm{B}$ & $\mathrm{C}$ & TB & STB & SB & B & $\mathrm{C}$ & TB & STB \\
\hline \multicolumn{12}{|c|}{ AI5 Memperoleh Sumber Daya IT } \\
\hline \multicolumn{12}{|c|}{ AI5.1 Kendali Pemerolehan } \\
\hline 1. & $\begin{array}{l}\text { Bagaimana Sarpras dapat } \\
\text { mewujudkan segala sarana dan } \\
\text { prasarana yang dibutuhkan oleh } \\
\text { sekolah? }\end{array}$ & & & & & & & & & & \\
\hline 2. & $\begin{array}{l}\text { Bagaimana sarpras menjaga } \\
\text { setiap sarana yang terdapat pada } \\
\text { setiap kelas maupun lingkungan } \\
\text { sekolah }\end{array}$ & & & & & & & & & & \\
\hline \multicolumn{12}{|c|}{ AI5.2 Pengelolaan Kontrak Pemasok } \\
\hline 1. & $\begin{array}{l}\text { Bagaimana pihak sekolah } \\
\text { mengelola sarana dan prasarana } \\
\text { agar barang yang tersedia dapat } \\
\text { tejaga dan terdata secara baik? }\end{array}$ & & & & & & & & & & \\
\hline 2. & $\begin{array}{l}\text { Bagaimana tanggungjawab pihak } \\
\text { sarpras apabila terjadi kerusakan } \\
\text { atau kehilangan pada sarana dan } \\
\text { prasarana sekolah }\end{array}$ & & & & & & & & & & \\
\hline \multicolumn{12}{|c|}{ AI5.3 Pemilihan Pemasok } \\
\hline 1. & $\begin{array}{l}\text { bagaimana pihak sekolah } \\
\text { memenuhi sarana dan prasarana } \\
\text { yang dibutuhkan sekolah }\end{array}$ & & & & & & & & & & \\
\hline 2. & $\begin{array}{l}\text { apakah sarana dan prasarana } \\
\text { sudah sesuai dengan kebutuhan } \\
\text { sekolah }\end{array}$ & & & & & & & & & & \\
\hline \multicolumn{12}{|c|}{ AI5.4 Memperoleh Sumber Daya IT } \\
\hline 1. & $\begin{array}{l}\text { apakah sarana dan prasarana } \\
\text { dapat terjaga dengan baik sesuai } \\
\text { dengan syarat dan ketentuan yang } \\
\text { ada? }\end{array}$ & & & & & & & & & & \\
\hline 2. & $\begin{array}{l}\text { Apakah sarana dan prasana sudah } \\
\text { terpenuhi bagi pihak sekolah } \\
\text { maupun siswa }\end{array}$ & & & & & & & & & & \\
\hline
\end{tabular}




\section{Quisioner User P04}

\begin{tabular}{|c|c|c|c|c|c|c|c|c|c|c|c|}
\hline \multirow{2}{*}{ No. } & \multirow{2}{*}{ Persyaratan } & \multicolumn{5}{|c|}{ Performance } & \multicolumn{5}{|c|}{ Expectasi } \\
\hline & & SB & B & $\mathrm{C}$ & TB & STR & SB & $\mathrm{B}$ & $\mathrm{C}$ & TB & STR \\
\hline \multicolumn{12}{|c|}{ P04 Mendefinisikan Proses TI,Organisasi,Dan Hubungan TI } \\
\hline \multicolumn{12}{|c|}{ P04.1 Rangka Proses IT } \\
\hline 1. & $\begin{array}{l}\text { Apakah informasi yang } \\
\text { diberikan pihak sarpras secara } \\
\text { terkomputerisasi telah sesuai } \\
\text { dengan ketentuan yang ada?. }\end{array}$ & & & & & & & & & & \\
\hline 2. & $\begin{array}{l}\text { bagaimana siswa memahami } \\
\text { penyusunan sarana dan } \\
\text { prasarana yang telah dibuat } \\
\text { oleh pihak sekolah }\end{array}$ & & & & & & & & & & \\
\hline \multicolumn{12}{|c|}{ P04.2 Komite strategi IT } \\
\hline 1. & $\begin{array}{l}\text { Apakah keterangan sarana dan } \\
\text { prasarana yang diterapkan } \\
\text { secara manual atau secara } \\
\text { online telah dimengerti oleh } \\
\text { siswa? }\end{array}$ & & & & & & & & & & \\
\hline 2. & $\begin{array}{l}\text { apakah siswa telah memahami } \\
\text { isi dari sarana dan prasarana } \\
\text { yang terdapat pada website } \\
\text { sekolah }\end{array}$ & & & & & & & & & & \\
\hline \multicolumn{12}{|c|}{ P04.3 Komite pengarah IT } \\
\hline 1. & $\begin{array}{l}\text { Bagaimana siswa dapat } \\
\text { mengetahui tentang apasaja } \\
\text { yang didapatkan pada saat } \\
\text { ajaran baru }\end{array}$ & & & & & & & & & & \\
\hline 2. & $\begin{array}{l}\text { apakah siswa telah menjaga } \\
\text { sarana dan prasarana yang } \\
\text { telah disediakan oleh pihak } \\
\text { sekolah }\end{array}$ & & & & & & & & & & \\
\hline \multicolumn{12}{|c|}{ P04.4 Penempatan Organisasi Pada Fungsi TI } \\
\hline 1. & $\begin{array}{l}\text { Apakah sarana dan prasarana } \\
\text { sudah sesuai dengan apa } \\
\text { kebutuhan sekolah. }\end{array}$ & & & & & & & & & & \\
\hline 2. & $\begin{array}{l}\text { bagaimana siswa dapat } \\
\text { mengetahui informasi sarana } \\
\text { dan prasarana baru secara } \\
\text { online }\end{array}$ & & & & & & & & & & \\
\hline \multicolumn{12}{|c|}{ P04.5 Struktur Organisasi IT } \\
\hline 1. & $\begin{array}{l}\text { apakah struktur organisasi } \\
\text { sarpras sudah berjalan dengan } \\
\text { baik bagi siswa }\end{array}$ & & & & & & & & & & \\
\hline 2. & $\begin{array}{l}\text { apakah siswa dilibatkan dalam } \\
\text { hal mewujudkan sebuah } \\
\text { sarana dan prasarana }\end{array}$ & & & & & & & & & & \\
\hline
\end{tabular}




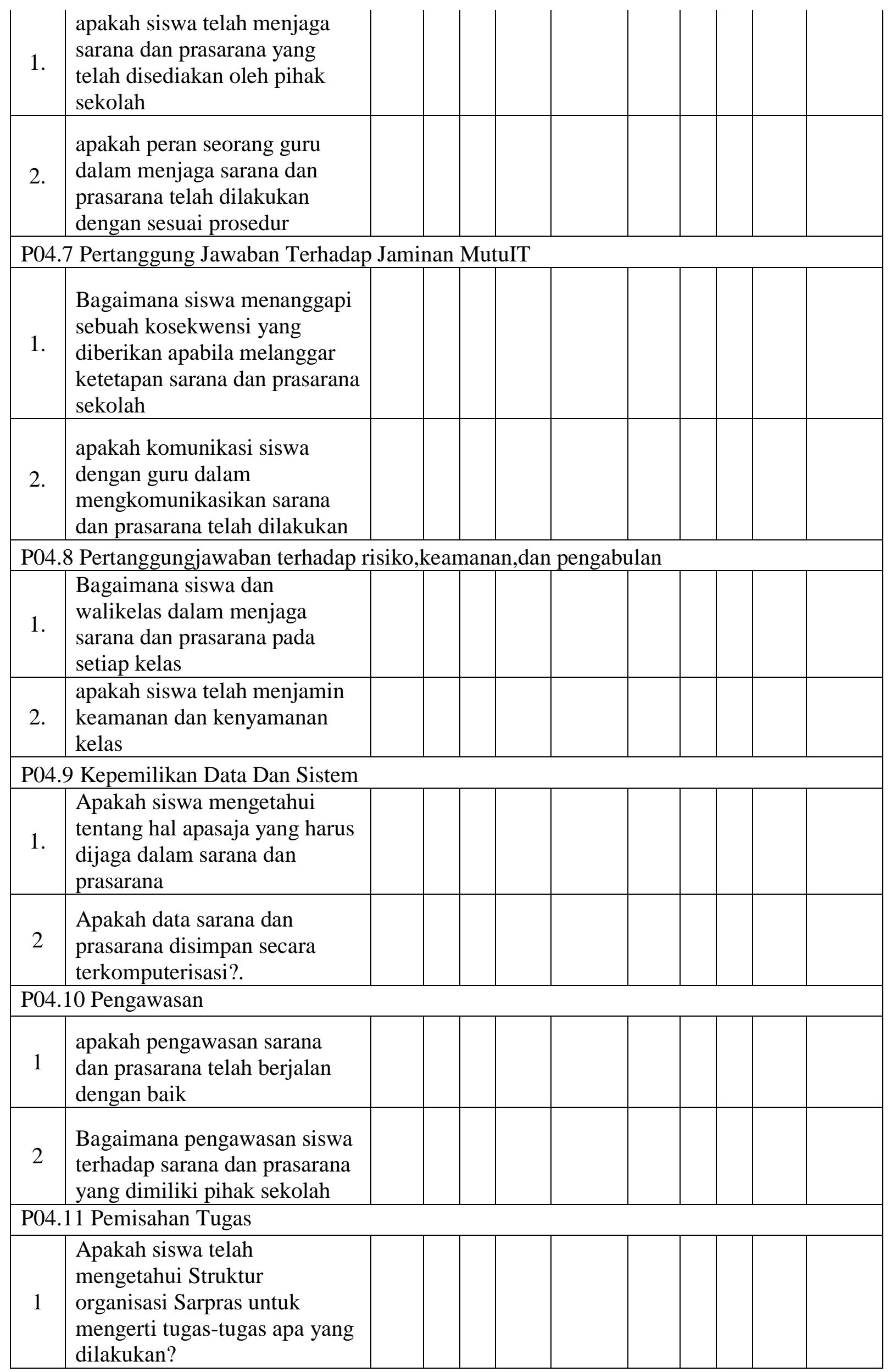



Apakah data yang dicantumkan sesuai dengan ketentuan yang berlaku

\section{Quisioner User AI5}

\begin{tabular}{|c|c|c|c|c|c|c|c|c|c|c|c|}
\hline \multirow{2}{*}{ No. } & \multirow{2}{*}{ Persyaratan } & \multicolumn{5}{|c|}{ Performance } & \multicolumn{5}{|c|}{ Expectasi } \\
\hline & & SB & $\mathrm{B}$ & $\mathrm{C}$ & $\mathrm{TB}$ & STB & $\mathrm{SB}$ & B & $\mathrm{C}$ & $\mathrm{TB}$ & STB \\
\hline \multicolumn{12}{|c|}{ AI5 Memperoleh Sumber Daya IT } \\
\hline \multicolumn{12}{|c|}{ AI5.1 Kendali Pemerolehan } \\
\hline 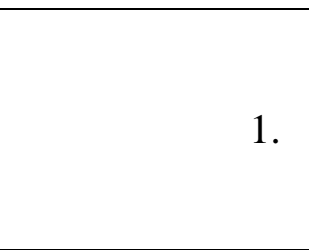 & $\begin{array}{l}\text { apakah sarana } \\
\text { dan prasarana } \\
\text { sekolah sudah } \\
\text { terkelola } \\
\text { dengan baik }\end{array}$ & & & & & & & & & & \\
\hline 2. & $\begin{array}{l}\text { Bagaimana } \\
\text { siswa menjaga } \\
\text { setiap sarana } \\
\text { yang terdapat } \\
\text { pada setiap } \\
\text { kelas maupun } \\
\text { lingkungan } \\
\text { sekolah }\end{array}$ & & & & & & & & & & \\
\hline \multicolumn{12}{|c|}{ AI5.2 Pengelolaan Kontrak Pemasok } \\
\hline 1. & $\begin{array}{l}\text { apakah siswa } \\
\text { telah } \\
\text { mengelola } \\
\text { sarana dan } \\
\text { prasarana agar } \\
\text { barang yang } \\
\text { tersedia dapat } \\
\text { tejaga dan } \\
\text { terdata secara } \\
\text { baik? }\end{array}$ & & & & & & & & & & \\
\hline 2. & $\begin{array}{l}\text { Bagaimana } \\
\text { tanggungjawab } \\
\text { siswa apabila } \\
\text { terjadi } \\
\text { kerusakan atau } \\
\text { kehilangan } \\
\text { pada sarana } \\
\text { dan prasarana } \\
\text { sekolah }\end{array}$ & & & & & & & & & & \\
\hline \multicolumn{12}{|c|}{ AI5.3 Pemilihan Pemasok } \\
\hline 1. & $\begin{array}{l}\text { Apakah dalam } \\
\text { penginputan } \\
\text { data terbaru } \\
\text { tentang sarana } \\
\text { dan prasarana } \\
\text { sekolah sudah } \\
\text { secara }\end{array}$ & & & & & & & & & & \\
\hline
\end{tabular}




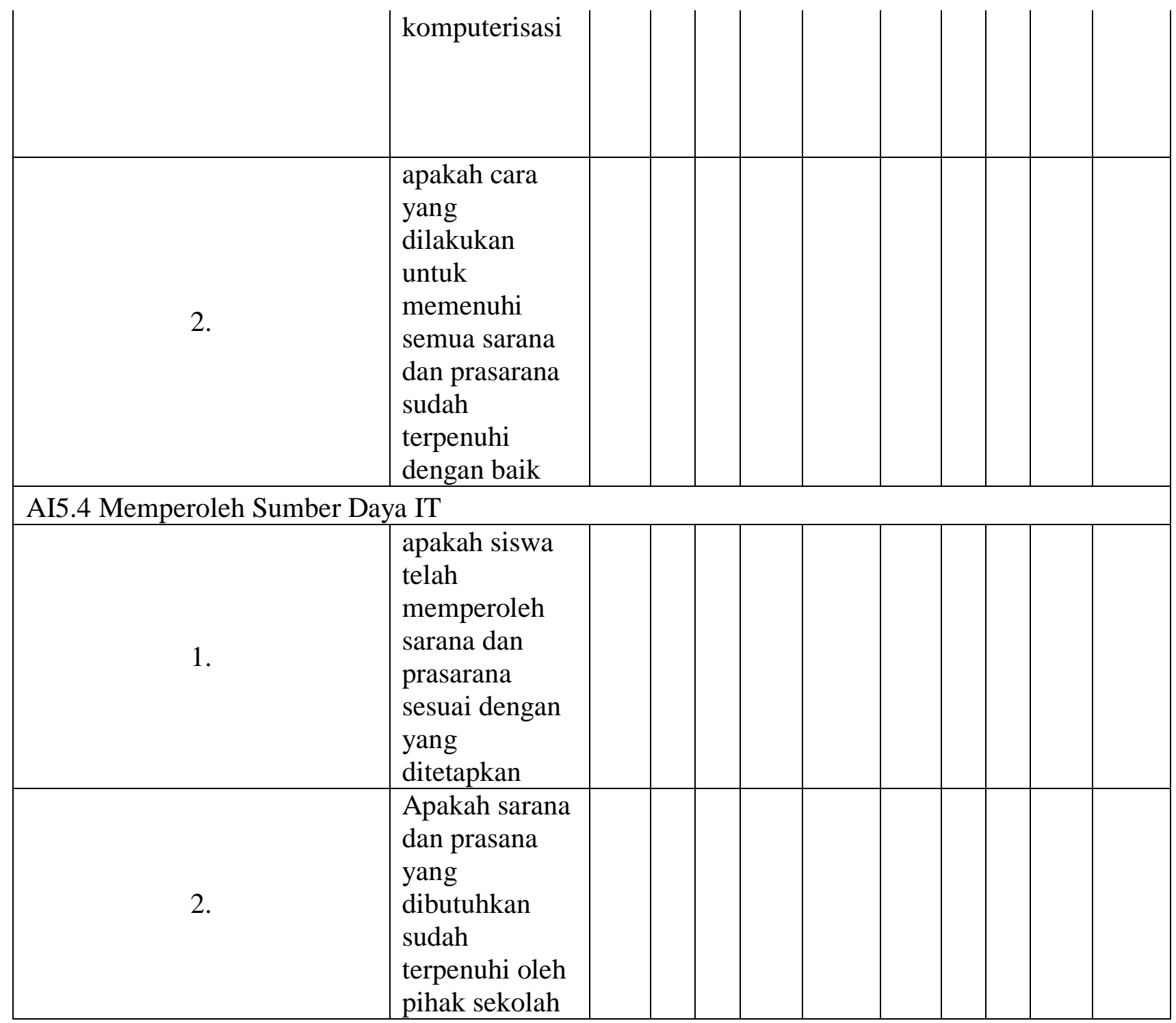




\section{BAB IV}

REKAP HASIL KUESIONER

USER

\begin{tabular}{|c|c|c|c|c|c|c|c|c|c|c|c|c|c|c|}
\hline & \multicolumn{7}{|c|}{ PERFORMANCE } & \multicolumn{6}{|c|}{ EXPECTED } \\
\hline & & No & SB & B & C & TB & STB & JLH & SB & B & C & TB & STB & ILH \\
\hline 1 & p04.1 & 1,1 & & 9 & & & & 9 & s & & & & & 9 \\
\hline 2 & & 1,2 & & 9 & & & & 9 & s & & & & & 9 \\
\hline 3 & p04.2 & 2,1 & & 5 & 4 & & & 9 & 5 & 4 & & & & 9 \\
\hline 4 & & 2,2 & & & 9 & & & 9 & 2 & 5 & & & & 9 \\
\hline 5 & p04.3 & 3,1 & & 4 & 5 & & & 9 & 9 & & & & & 9 \\
\hline 6 & & 3,2 & 5 & 4 & & & & 9 & S & & & & & 9 \\
\hline 7 & P04.4 & 4,1 & 4 & 5 & & & & 9 & s & & & & & 9 \\
\hline 8 & & 4,2 & & 9 & & & & 9 & S & & & & & 9 \\
\hline 9 & P04.5 & 5,1 & 5 & 4 & & & & 9 & S & & & & & 9 \\
\hline 10 & & 5,2 & 5 & 4 & & & & 9 & s & & & & & 9 \\
\hline 11 & P04.6 & 6,1 & 9 & & & & & 9 & s & & & & & 9 \\
\hline 12 & & 6,2 & & 9 & & & & 9 & 5 & 4 & & & & 9 \\
\hline 13 & P04.7 & 7,1 & & 9 & & & & 9 & s & & & & & 9 \\
\hline 14 & & 7,2 & 5 & & 4 & & & 9 & 5 & 4 & & & & 9 \\
\hline 15 & P04.8 & 8,1 & 4 & 5 & & & & 9 & s & & & & & 9 \\
\hline 16 & & 8,2 & 9 & & & & & 9 & s & & & & & 9 \\
\hline 17 & P04.9 & 9,1 & & 9 & & & & 9 & s & & & & & 9 \\
\hline 18 & & 9,2 & 5 & 4 & & & & 9 & s & & & & & 9 \\
\hline 19 & P04.10 & 10,1 & 5 & 4 & & & & 9 & s & & & & & 9 \\
\hline 20 & & 10,2 & 4 & 5 & & & & 9 & s & & & & & 9 \\
\hline 21 & P04.11 & 11,1 & 9 & & & & & 9 & 5 & 4 & & & & 9 \\
\hline 22 & & 11,2 & & & 9 & & & 9 & 2 & 5 & & & & 9 \\
\hline 23 & Al5.1 & 1,1 & 9 & & & & & 9 & s & & & & & 9 \\
\hline 24 & & 1,2 & & 9 & & & & 9 & S & & & & & 9 \\
\hline 25 & Al5.2 & 2,1 & 4 & 5 & & & & 9 & S & & & & & 9 \\
\hline 26 & & 2,2 & 5 & 4 & & & & 9 & S & & & & & 9 \\
\hline 27 & Al5.3 & 3,1 & & 5 & 4 & & & 9 & 5 & 4 & & & & 9 \\
\hline 28 & & 3,2 & & 9 & & & & 9 & 5 & 4 & & & & 9 \\
\hline 29 & Al5.4 & 4,1 & & 9 & & & & 9 & 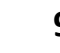 & & & & & 9 \\
\hline 30 & & 4,2 & & 9 & & & & 9 & s & & & & & 9 \\
\hline
\end{tabular}

\begin{tabular}{|rr|rl|l|}
\hline \multicolumn{4}{|c|}{ PERFORMANCE } & \multicolumn{2}{|c|}{ EXPECTED } & \multirow{2}{*}{ gap } \\
\cline { 1 - 3 } ACTIVITY & PROSES & ACTIVITY & PROSES & \\
\cline { 1 - 3 } 2,40 & 2,40 & 3,00 & \multirow{2}{*}{3,00} & \\
2,40 & & 3,00 & & 0,60 \\
2,13 & 1,97 & 2,73 & 2,70 & \\
1,80 & & 2,67 & & 0,73 \\
2,07 & 2,40 & 3,00 & 3,00 & \\
2,73 & & 3,00 & & 0,60 \\
2,67 & 2,53 & 3,00 & 3,00 & 0,47 \\
\hline
\end{tabular}




\begin{tabular}{|c|c|c|c|c|}
\hline 2,40 & & 3,00 & & \\
\hline 2,73 & \multirow{2}{*}{2,73} & 3,00 & \multirow{2}{*}{3,00} & \\
\hline 2,73 & & 3,00 & & 0,27 \\
\hline 3,00 & \multirow{2}{*}{2,70} & 3,00 & \multirow{2}{*}{2,87} & \\
\hline 2,40 & & 2,73 & & 0,17 \\
\hline 2,40 & \multirow{2}{*}{2,43} & 3,00 & \multirow{2}{*}{2,87} & \\
\hline 2,47 & & 2,73 & & 0,43 \\
\hline 2,67 & \multirow{2}{*}{2,83} & 3,00 & \multirow{2}{*}{3,00} & \\
\hline 3,00 & & 3,00 & & 0,17 \\
\hline 2,40 & \multirow{2}{*}{2,57} & 3,00 & \multirow{2}{*}{3,00} & \\
\hline 2,73 & & 3,00 & & 0,43 \\
\hline 2,73 & \multirow{2}{*}{2,70} & 3,00 & \multirow{2}{*}{3,00} & \\
\hline 2,67 & & 3,00 & & 0,30 \\
\hline 3,00 & \multirow{2}{*}{2,40} & 2,73 & \multirow{2}{*}{2,70} & \\
\hline 1,80 & & 2,67 & & 0,30 \\
\hline 3,00 & \multirow{2}{*}{2,70} & 3,00 & \multirow{2}{*}{3,00} & \\
\hline 2,40 & & 3,00 & & 0,30 \\
\hline 2,67 & \multirow{2}{*}{2,70} & 3,00 & \multirow{2}{*}{3,00} & \\
\hline 2,73 & & 3,00 & & 0,30 \\
\hline 2,13 & \multirow{2}{*}{2,27} & 2,73 & \multirow{2}{*}{2,73} & \\
\hline 2,40 & & 2,73 & & 0,47 \\
\hline 2,40 & \multirow{2}{*}{2,40} & 3,00 & \multirow{2}{*}{3,00} & \\
\hline 2,40 & & 3,00 & & 0,60 \\
\hline
\end{tabular}

REKAP HASIL KUESIONER

MANAGEMENT

PERFORMANCE

\begin{tabular}{|c|c|c|c|c|c|c|c|c|c|c|c|c|}
\hline & \\
\hline No & SB & B & C & TB & STB & JLH & SB & $B$ & $C$ & TB & STB & JLH \\
\hline 1,1 & & 4 & & & & 4 & 2 & & & & & 4 \\
\hline 1,2 & & 4 & & & & 4 & 4 & & & & & 4 \\
\hline 2,1 & & & 4 & & & 4 & & 4 & & & & 4 \\
\hline 2,2 & & & 4 & & & 4 & & 4 & & & & 4 \\
\hline 3,1 & & 4 & & & & 4 & & 4 & & & & 4 \\
\hline 3,2 & 4 & & & & & 4 & 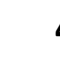 & & & & & 4 \\
\hline 4,1 & & 4 & & & & 4 & 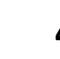 & & & & & 4 \\
\hline 4,2 & 4 & & & & & 4 & & & & & & 4 \\
\hline 5,1 & & 4 & & & & 4 & 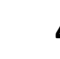 & & & & & 4 \\
\hline 5,2 & & & 4 & & & 4 & & & & & & 4 \\
\hline 6,1 & & 4 & & & & 4 & 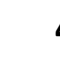 & & & & & 4 \\
\hline 6,2 & & 4 & & & & 4 & 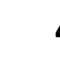 & & & & & 4 \\
\hline 7,1 & & & 4 & & & 4 & 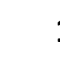 & 3 & & & & 4 \\
\hline 7,2 & & 4 & & & & 4 & & & & & & 4 \\
\hline 8,1 & & 4 & & & & 4 & & & & & & 4 \\
\hline 8,2 & 4 & & & & & 4 & & & & & & 4 \\
\hline 9,1 & 4 & & & & & 4 & & & & & & 4 \\
\hline 9,2 & 4 & & & & & 4 & & & & & & 4 \\
\hline
\end{tabular}




\begin{tabular}{|c|c|c|c|c|c|c|c|}
\hline 19 & P04.10 & 10,1 & 4 & & 4 & 4 & 4 \\
\hline 20 & & 10,2 & 4 & & 4 & 4 & 4 \\
\hline 21 & P04.11 & 11,1 & & 4 & 4 & 4 & 4 \\
\hline 22 & & 11,2 & & 4 & 4 & 4 & 4 \\
\hline 23 & Al5.1 & 1,1 & 1 & 3 & 4 & 4 & 4 \\
\hline 24 & & 1,2 & & 4 & 4 & 4 & 4 \\
\hline 25 & Al5.2 & 2,1 & & 4 & 4 & 4 & 4 \\
\hline 26 & & 2,2 & 4 & & 4 & 4 & 4 \\
\hline 27 & Al5.3 & 3,1 & & 4 & 4 & 4 & 4 \\
\hline 28 & & 3,2 & & 4 & 4 & 4 & 4 \\
\hline 29 & Al5.4 & 4,1 & 4 & & 4 & 4 & 4 \\
\hline 30 & & 4,2 & 1 & 3 & 4 & 4 & 4 \\
\hline
\end{tabular}

\begin{tabular}{|c|c|c|c|c|}
\hline \multicolumn{2}{|c|}{ PERFORMANCE } & \multicolumn{2}{|c|}{ EXPECTED } & \multirow{3}{*}{ gap } \\
\hline \multicolumn{4}{|c|}{ MATURITY } & \\
\hline ACTIVITY & PROSES & ACTIVITY & PROSES & \\
\hline 3,20 & \multirow{2}{*}{3,20} & 4,00 & \multirow{2}{*}{4,00} & \multirow[b]{2}{*}{0,80} \\
\hline 3,20 & & 4,00 & & \\
\hline 2,40 & \multirow{2}{*}{2,40} & 3,20 & \multirow{2}{*}{3,20} & \multirow[b]{2}{*}{0,80} \\
\hline 2,40 & & 3,20 & & \\
\hline 3,20 & \multirow{2}{*}{3,60} & 3,20 & \multirow{2}{*}{3,60} & \multirow[b]{2}{*}{0,00} \\
\hline 4,00 & & 4,00 & & \\
\hline 3,20 & \multirow{2}{*}{3,60} & 4,00 & \multirow{2}{*}{4,00} & \multirow[b]{2}{*}{0,40} \\
\hline 4,00 & & 4,00 & & \\
\hline 3,20 & \multirow{2}{*}{2,80} & 4,00 & \multirow{2}{*}{4,00} & \multirow[b]{2}{*}{1,20} \\
\hline 2,40 & & 4,00 & & \\
\hline 3,20 & \multirow{2}{*}{3,20} & 4,00 & \multirow{2}{*}{4,00} & \multirow[b]{2}{*}{0,80} \\
\hline 3,20 & & 4,00 & & \\
\hline 2,40 & \multirow{2}{*}{2,80} & 3,40 & \multirow{2}{*}{3,70} & \multirow[b]{2}{*}{0,90} \\
\hline 3,20 & & 4,00 & & \\
\hline 3,20 & \multirow{2}{*}{3,60} & 4,00 & \multirow{2}{*}{4,00} & \multirow[b]{2}{*}{0,40} \\
\hline 4,00 & & 4,00 & & \\
\hline 4,00 & \multirow{2}{*}{4,00} & 4,00 & \multirow{2}{*}{4,00} & \\
\hline 4,00 & & 4,00 & & 0,00 \\
\hline 4,00 & 4.00 & 4,00 & 4.00 & \\
\hline 4,00 & & 4,00 & & 0,00 \\
\hline 3,20 & 3,20 & 4,00 & 4,00 & \\
\hline 3,20 & & 4,00 & & 0,80 \\
\hline 3,40 & 3,30 & 4,00 & 400 & \\
\hline 3,20 & (3, & 4,00 & 4,00 & 0,70 \\
\hline 3,20 & 3.60 & 4,00 & 4.00 & \\
\hline 4,00 & & 4,00 & & 0,40 \\
\hline 3,20 & 320 & 4,00 & 400 & \\
\hline 3,20 & 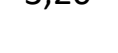 & 4,00 & (1) & 0,80 \\
\hline 4,00 & 3.70 & 4,00 & 400 & \\
\hline 3,40 & 8,70 & 4,00 & 4,0 & 0,30 \\
\hline
\end{tabular}




\section{Perhitungan User \& Manajement}

CURRENT Expectacy

USER MGT User MGT

$\begin{array}{lllll}\text { PO4.1 } & 2,40 & 4,00 & 3,00 & 4,00 \\ \text { PO4.2 } & 1,97 & 3,20 & 2,70 & 3,20 \\ \text { PO4.3 } & 2,40 & 3,20 & 3,00 & 3,60 \\ \text { PO4.4 } & 2,53 & 4,00 & 3,00 & 4,00 \\ \text { PO4.5 } & 2,73 & 4,00 & 3,00 & 4,00 \\ \text { PO4.6 } & 2,70 & 4,00 & 2,87 & 4,00 \\ \text { PO4.7 } & 2,43 & 3,40 & 2,87 & 3,70 \\ \text { PO4.8 } & 2,83 & 4,00 & 3,00 & 4,00 \\ \text { PO4.9 } & 2,57 & 4,00 & 3,00 & 4,00 \\ \text { PO4.10 } & 2,70 & 4,00 & 3,00 & 4,00 \\ \text { PO4.11 } & 2,40 & 4,00 & 2,70 & 4,00 \\ \text { AI5.1 } & 2,70 & 4,00 & 3,00 & 4,00 \\ \text { AI5.2 } & 2,70 & 4,00 & 3,00 & 4,00 \\ \text { Al5.3 } & 2,27 & 4,00 & 2,73 & 4,00 \\ \text { Al5.4 } & 2,40 & 4,00 & 3,00 & 4,00\end{array}$

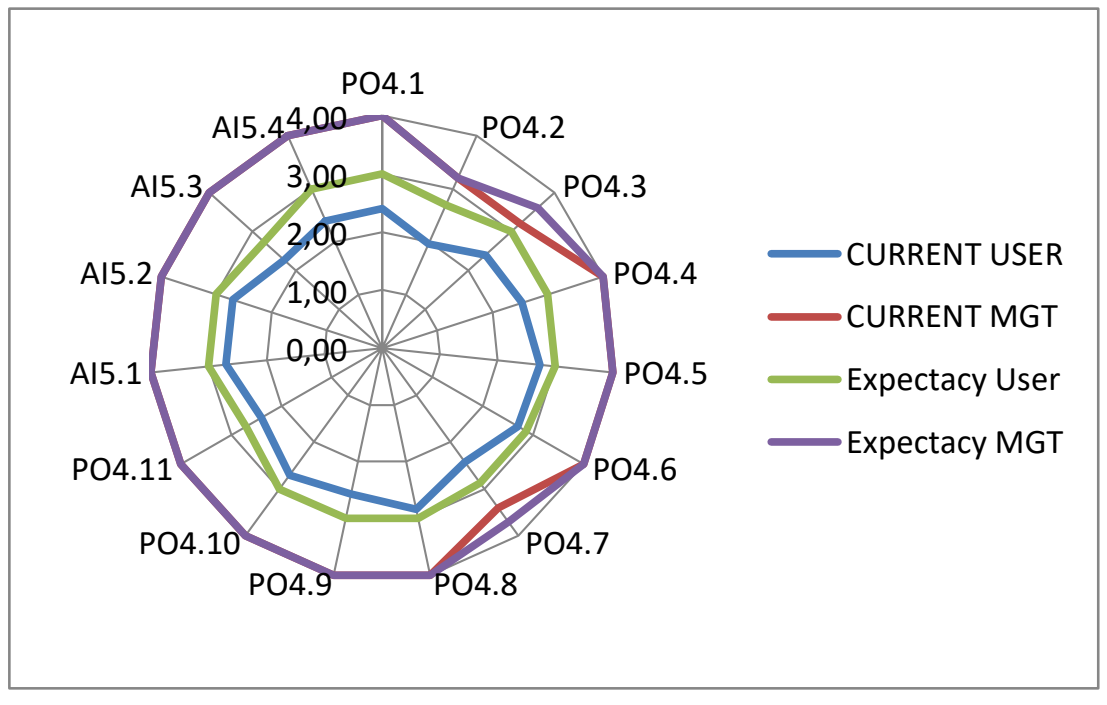

\section{Perhitungan USER}

$\begin{array}{lrr} & \begin{array}{r}\text { CURRENT } \\ \text { USER }\end{array} & \begin{array}{c}\text { Expectacy } \\ \text { User }\end{array} \\ \text { P04.1 } & 2,40 & 3,00 \\ \text { P04.2 } & 1,97 & 2,73 \\ \text { P04.3 } & 2,40 & 3,00 \\ \text { P04.4 } & 2,53 & 3,00 \\ \text { P04.5 } & 2,73 & 3,00 \\ \text { P04.6 } & 2,70 & 3,00 \\ \text { P04.7 } & 2,43 & 3,00 \\ \text { P04.8 } & 2,83 & 3,00 \\ \text { P04.9 } & 2,57 & 3,00 \\ \text { P04.10 } & 2,70 & 3,00 \\ \text { P04.11 } & 2,40 & 2,73 \\ \text { Al5.1 } & 2,70 & 3,00 \\ \text { A15.2 } & 2,70 & 3,00 \\ \text { A15.3 } & 2,40 & 3,00 \\ \text { AI5.4 } & 0,00 & 0,00\end{array}$

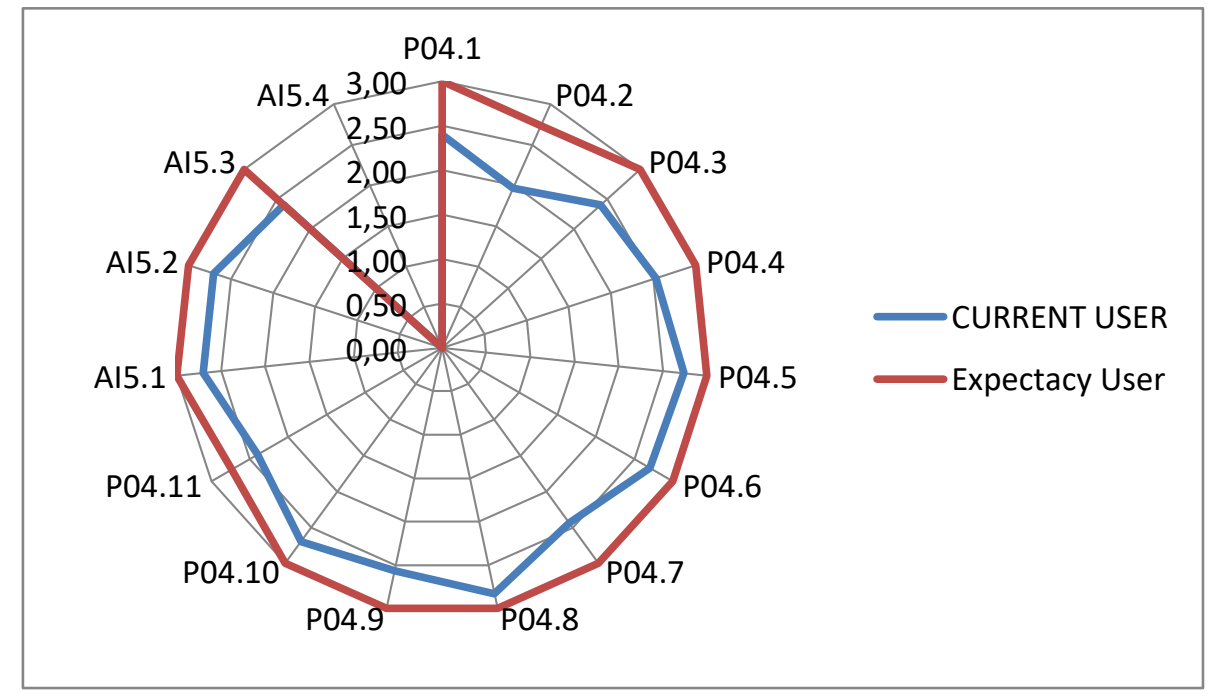




\section{Perhitungan Manajement}

$\begin{array}{cc}\text { CURRENT } & \text { Expectacy } \\ \text { MGT } & \text { MGT } \\ 4,00 & 4,00 \\ 3,20 & 3,20 \\ 3,20 & 3,60 \\ 4,00 & 4,00 \\ 4,00 & 4,00 \\ 4,00 & 4,00 \\ 3,40 & 3,70 \\ 4,00 & 4,00 \\ 4,00 & 4,00 \\ 4,00 & 4,00 \\ 4,00 & 4,00 \\ 4,00 & 4,00 \\ 4,00 & 4,00 \\ 4,00 & 4,00 \\ 4,00 & 4,00\end{array}$

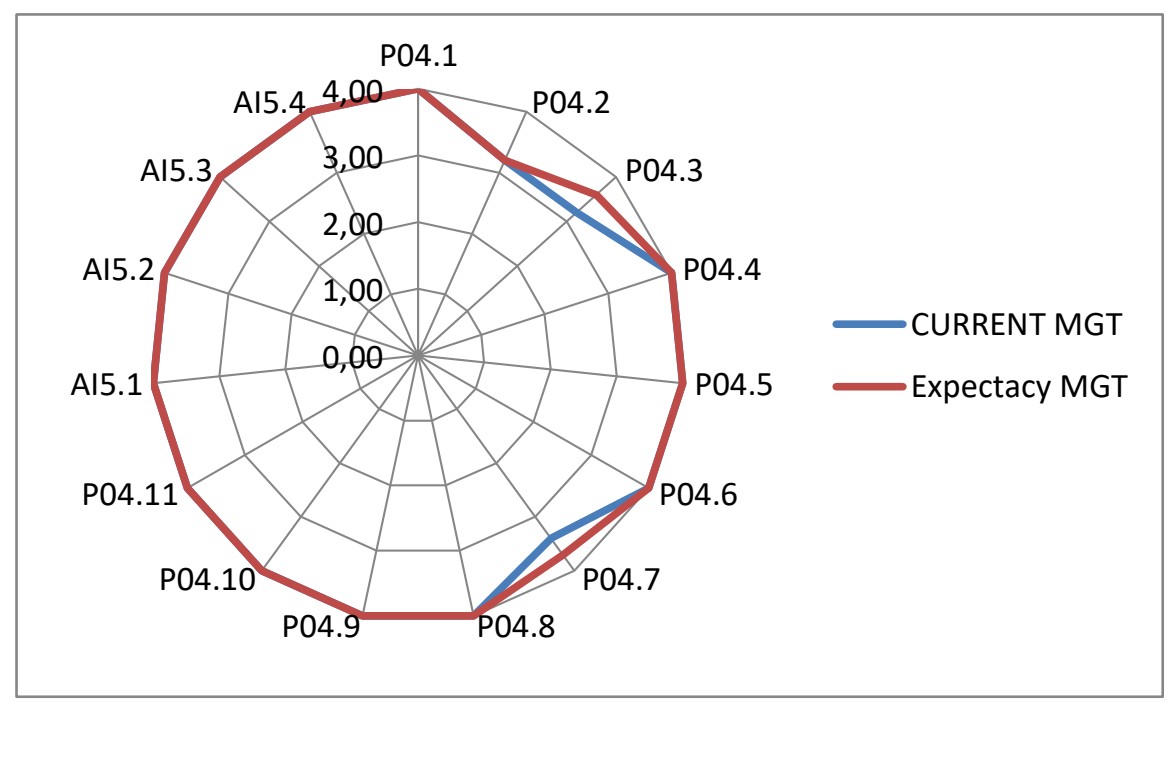




\section{BAB V}

\section{Saran}

- Lebih baik lagi dalam menjaga sarana dan prasarana

- Lebih detail dalam mendata sarana dan prasarana yang telah ada

○ Lebih mengutamakan apa yang menjadi kebutuhan sekolah

\section{Kesimpulan}

Dari hasil audit yang dilakukan di SMK FARMASI CENDIKIA FARMA HUSADA

sudah cukup baik dalam segi sarana dan prasarana yang berada dalam sekolah, hanya saja mungkin harus diperbaiki lagi dalam penyampaian informasi. 


\section{LAMPIRAN}
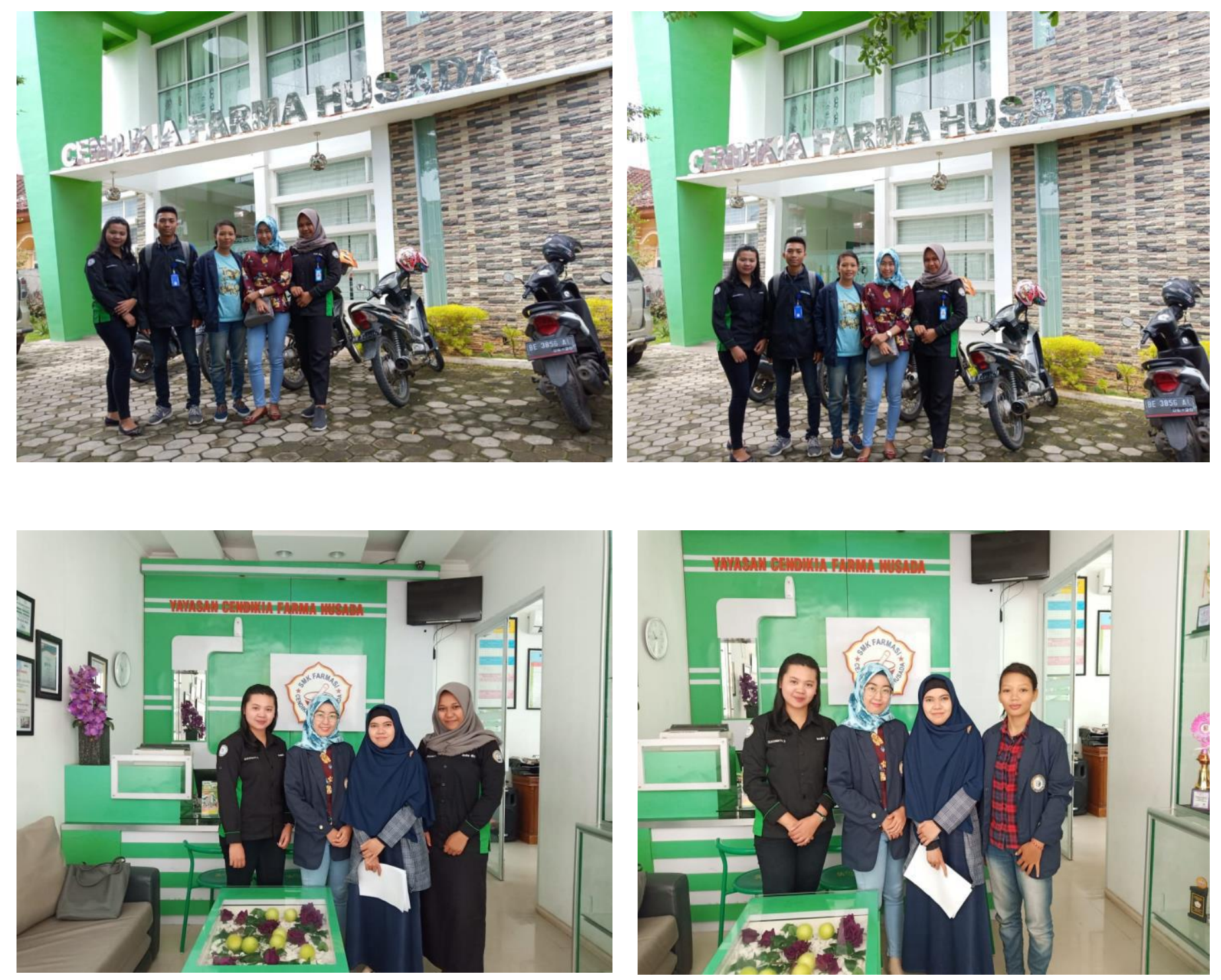

\section{"MOTTO"}

Karna langkah kakimu tidak akan pernah menghianatimu, percayalah bahwa perjuangan itu akan indah suatu saat nanti 